\title{
Placental damages from ultrasonic changes to histopathological findings in maturing placenta in pregnancy complicated with hypertension: an observational clinical study
}

\author{
Amit Dutta ${ }^{1 *}$, Ramesh Kumar Sahu ${ }^{2}$, Kripasindhu Chatterjee ${ }^{3}$, Sanjay Kothari ${ }^{2}$, \\ S. K. Rafikul Rahaman ${ }^{3}$, Shipra Sen ${ }^{4}$
}

\begin{abstract}
${ }^{1}$ Department of Obstetrics and Gynecology, ${ }^{2}$ Department of Radiodiagnosis, ${ }^{3}$ Department of Pediatrics, ${ }^{4}$ Department of Pathology, ICARE Institute of Medical Sciences and Research, Banbishnupur, Purba Medinipur, Haldia, West Bengal, India
\end{abstract}

Received: 06 April 2017

Accepted: 08 April 2017

\section{*Correspondence:}

Dr. Amit Dutta,

E-mail: amitbdn@gmail.com

Copyright: (c) the author(s), publisher and licensee Medip Academy. This is an open-access article distributed under the terms of the Creative Commons Attribution Non-Commercial License, which permits unrestricted non-commercial use, distribution, and reproduction in any medium, provided the original work is properly cited.

\section{ABSTRACT}

Background: The development of mild hypertension or preeclampsia at or near term is associated with minimal maternal and neonatal morbidities. Obstetric ultrasound provides a cornerstone to other modalities used for assessing hypertensive disorders of pregnancy. Placental architecture is modified in PE and eclampsia. This study was designed to detect the placental changes in hypertensive disorders of pregnancy and correlation with ultrasonic and histopathological changes.

Methods: The study group comprised of 42 patients with pregnancy complicated with hypertension with period of gestation above 20 weeks and B.P. more than 140/90 $\mathrm{mm}$ of $\mathrm{Hg}$ measured on two occasions 6 hours or more apart. The control group consists of 42 normotensive patients matched with age and parity. One ultrasonic examination was performed between 28 weeks and 34 weeks and another after 34 weeks till term. Apart from routine parameters i.e. BPD, AC, FL, Amniotic fluid index, EBW and gestational age routine placental grading were performed according to the classification proposed by Grannum and associates. To evaluate perinatal outcome following measurement were studied birth weight immediately after delivery, mode of delivery, perinatal morbidity and mortality, APGAR score, presence of fetal distress.

Results: In $97.62 \%$ cases (41 out of 42) of control group showed Grade-II changes as opposed to $57.14 \%$ of cases ( 24 out of 42) in study group before 34 weeks. All 21 cases in study group showing Grade 'III' changes before 34 weeks had infarction, calcification, increased syncytial knots, fibrinoid necrosis from 95.23 to $100 \%$ of these cases showed all these changes. Only 2 cases $(9.52 \%)$ showed perivascular hemorrhage having Grade 'III' before 34 weeks. Conclusions: Accelerated maturation of placenta in pregnancy complicated with hypertension are more common in the hypertensive group. Increased histopathological degenerative changes e.g. calcification, fibrinoid necrosis etc., are more marked even before 34 weeks of gestation in hypertensive group.

Keywords: Histopathological changes, Neonatal birth weight, Obstetric ultrasound, Placenta, Preeclampsia, Pregnancy, Pregnancy-induced hypertension

\section{INTRODUCTION}

Worldwide, $10 \%$ of all pregnancies are complicated by hypertension, with pre-eclampsia and eclampsia being the major causes of maternal and prenatal morbidity and mortality. ${ }^{1}$ It is also estimated that pregnancy induced hypertension $(\mathrm{PIH})$, one of the hypertensive disorders of pregnancy, affects about $5-8 \%$ of all pregnant women 
worldwide. $^{2}$ Pregnancy induced hypertension (PIH) is defined as $\mathrm{BP} \geq 140 / 90 \mathrm{mmHg}$, taken after a period of rest on two occasions or $\geq 160 / 110 \mathrm{mmHg}$ on one occasion in a previously normotensive woman. ${ }^{3}$

Hypertension is the most common medical problem encountered during pregnancy, complicating 2-3\% of pregnancies. Hypertension occurs in $8 \%$ of pregnancies and contributes to $18 \%$ of fetal and infant mortality rates and to about $40-50 \%$ of infant who are low birth weight. ${ }^{4}$ Pregnancy-induced hypertension (PIH) is the leading cause of maternal mortality and is an important factor in fetal wastage. Pregnancy complications like hypertension are reflected in placenta in a significant way both macroscopically and microscopically. Several studies have shown that utero-placental blood flow is decreased in PIH due to maternal vasospasm. ${ }^{5}$ This leads to constriction of fetal stem arteries and has been associated with the changes seen in the placenta of preeclamptic women. ${ }^{6}$ Maternal vasospasm leads to fetal hypoxia and accordingly it may lead to fetal distress and fetal death. ${ }^{7,8}$

FGR and PE are defined as placentally-related complications in a large proportion of cases, as they are often characterized by defective placental development (e.g. inadequate remodelling of maternal spiral arteries and altered uteroplacental blood perfusion). ${ }^{9}$ Therefore placental dysfunction is one of the underlying factors which contribute to PE and FGR, and consequently stillbirth. This offers a great opportunity to identify women at risk using biomarkers reflecting defective placentation. $^{10}$

Fetal growth is evaluated using ultrasonographic fetal biometry and calculation of estimated fetal weight (EFW). Placental function is assessed using Doppler flow velocimetry of the maternal uterine and fetal umbilical arteries. Flow resistance of the uterine artery decreases during the first half of pregnancy due to invasion of the maternal vessels by the trophoblast cells. Persistence of high resistance patterns of flow in both the uterine and umbilical artery in mid-gestation and in the third trimester of pregnancy has been associated with altered placental function and structure as well as increased risk of obstetric complications. ${ }^{11-14}$

Currently, these methods are applied selectively to women with pre-existing risk factors or acquired complications of pregnancy. However, the sensitivity of selective use of ultrasonography for detecting small babies is poor, in the region of $20-25 \% .^{15,16}$ In summary, obstetric ultrasound provides a cornerstone to other modalities used for assessing hypertensive disorders of pregnancy. Placental grading is an empirical classification introduced by Grannum and Hobbins. ${ }^{17}$ It is based on modification that appear in the chorionic plate, basal layer and the placental substance. Placental maturation and insufficiency is diagnosed by studying placental grading. This study was designed to detect the morbid changes in placenta in cases of pregnancy- induced hypertension (PIH) both ultrasonic and histopathologically.

\section{METHODS}

This study was conducted in the Department of Obstetrics and Gynaecology of a tertiary care teaching hospital, Haldia in the one year period of time November 2014 to November 2015 after taking permission from institutional ethics committee. The study group comprised of 42 patients with pregnancy complicated with hypertension with period of gestation above 20 weeks and B.P. more than $140 / 90 \mathrm{~mm}$ of $\mathrm{Hg}$ measured on two occasions 6 hours or more apart. The control group consists of 42 normotensive patients matched with age and parity. All patients were subjected to routine antenatal examination and ultrasonic examination were performed at least twice using Aloka Echo Model LS-280 machine. One ultrasonic examination were performed between 28 weeks and 34 weeks and another after 34 weeks till term. Apart from routine parameters i.e. BPD, AC, FL, Amniotic fluid index, EBW and gestational age routine placental grading were performed according to the classification proposed by Grannum and associates. ${ }^{17}$

Placenta was subjected for both gross and microscopic examination. The placenta was fixed in $10 \%$ formalin. From each specimen 5-6 whole thickness tissue blocks were taken. Section cut with the thickness of $5 .^{7}$ micrometer and then stained with conventional haematoxylin and eosin stain. Random fields were studied under microscope, following circulatory and parenchymatous changes were noted. In circulatory changes we had looked for infarcts, intervillous fibrin deposition, increased syncytial knots, enarteritis and villous oedema/fibrosis. In parenchymatous changes we had looked for hydropic changes, fibrinoid degeneration, basement membrane thickening and calcification and RP. clots. To evaluate perinatal outcome following measurement were studied-birth weight immediately after delivery, mode of delivery, perinatal morbidity and mortality, APGAR score, presence of fetal distress.

\section{RESULTS}

In the study, 42 cases of pregnancy complicated with hypertension and 42 normotensive cases were selected. Patients of both groups matched with age and parity. In present study incident of placental grading is presented in this Graph-I and Graph-II. Placental grade-III changes were demonstrated before 34 weeks in $38.09 \%$ of cases, (16 out of 42) whereas none of control group shows grade III placental maturity before 34 weeks.

In $97.62 \%$ cases (41 out of 42) of control group showed Grade-II changes as opposed to $57.14 \%$ of cases (24 out of 42) in study group before 34 weeks. We had one case $(4.34 \%)$ showing Grade-I changes at 30 weeks, where extensive calcification was seen, which had to be terminated because of uncontrolled blood pressure and 
intrauterine death. In the study group $16.67 \%$ (7 out of 42 patients) had Grade-III placenta after 34 weeks and $80.95 \%$ (34 out of 42 patients) had Grade III placenta after 34 weeks.

Thus, the premature finding of Grade-III changes in hypertensive group may be due to placental dysfunction and senescence rather than just normal maturity of progress. Thus, variety of Grade-III changes in uncomplicated pregnancy supports this study. Study group was divided into mild PIH where BP below 160/110 $\mathrm{mm}$ of $\mathrm{Hg}$, and severe PIH above 160/110 mm of $\mathrm{Hg}$.

So far as mode of delivery is concerned in control group, operative intervention was not required in 36 cases $(85.71 \%)$. Only 6 cases $(14.28 \%)$ required operative intervention. Of which, 1 case $(16.6 \%)$ had LSCS for occipito-posterior presentation with fetal distress and the
5 cases $(83.33 \%)$ required outlet forceps delivery due to obstetric indications. About 2 cases (32.31\%) had prolonged 2nd stage and 3 cases (50\%) had foetal distress. In the study group, $11(26.20 \%)$ had preterm delivery and 31 cases $(73.80 \%)$ cases had full term delivery. Ten cases $(23.8 \%)$ in the study group were taken directly for LSCS, indications being uncontrolled hypertension, primi with breech, previous two LSCS, previous LSCS for CPD, previous LSCS with hypertension. Remaining 32 cases (76.19\%) of study group 17 cases $(40.47 \%)$ were induced and 15 cases $(35.71 \%)$ went into spontaneous labour. Of the induced group 15 cases $(95.34 \%)$ operative intervention was required. Of these, 8 cases $(53.33 \%)$ were taken for caesarean section, the indication being either failure of induction or foetal distress $6(35.2 \%)$. Remaining 7 cases $(46.67 \%)$ had outlet forceps delivery for foetal distress 4 (26.6\%) or prophylactic $3(20 \%)$.

Table 1: Feto-placental ratio in case and control group.

\begin{tabular}{|llll|l|}
\hline Group & No of cases & Birth weight (grams) & Placental weight (grams) & F.P. Ratio \\
\hline Control & 42 & 2720 & 461.2 & 5.9 \\
\hline B.P $<160 / 110$ & 28 & 2600 & 473.9 & 5.4 \\
\hline B.P $>160 / 110$ & 14 & 2060 & 390.0 & 5.2 \\
\hline
\end{tabular}

Table 2: Histopathological changes in placenta with ultrasound grading in study group.

\begin{tabular}{|llllll|}
\hline HPR & Less than 34 weeks $[\mathbf{n = 2 1}]$ & \multicolumn{1}{l}{ More than 34 weeks $(\mathbf{n = 1 9})$} & Total \\
& Gr. II & Gr. III & Gr. II & Gr. III & \\
\hline Infarction & - & $20(95.23 \%)$ & - & $13(68.42 \%)$ & $33(78.57 \%)$ \\
\hline Calcification & - & $21(100 \%)$ & - & $8(42.10 \%)$ & $29(69.04 \%)$ \\
\hline Increased syn. knots & - & $21(100 \%)$ & - & $10(52.63 \%)$ & $31(73.80 \%)$ \\
\hline Fibrinoid necrosis & - & $20(95.23 \%)$ & - & $17(89.47 \%)$ & $37(88.09 \%)$ \\
\hline Perivasc. haemorrhage & - & $2(9.52 \%)$ & - & $1(5.26 \%)$ & $3(7.14 \%)$ \\
\hline Subchorionic haemorrhage & - & - & - & $5(26.31 \%)$ & $5(11.90 \%)$ \\
\hline
\end{tabular}

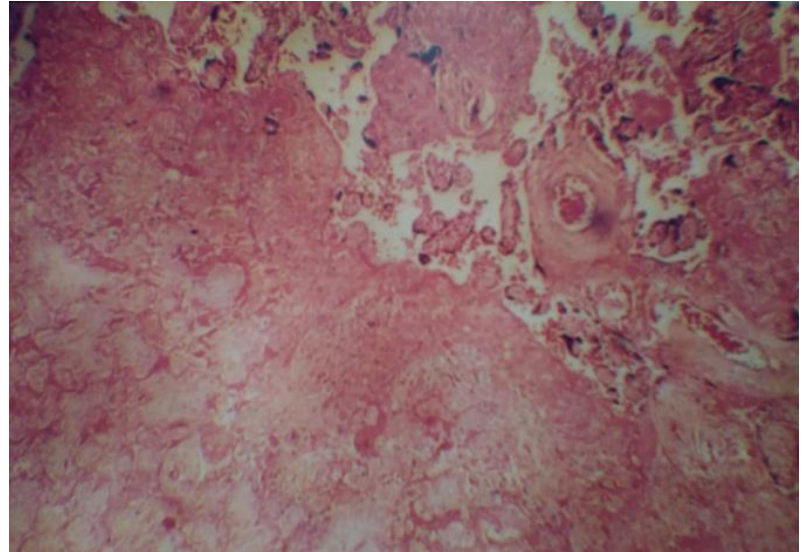

Figure 1: Pathology of human placenta in PIH. Showing placental infarction in patient with pregnancy induced hypertension.
As it is seen in the above table feto-placental, ratio in study group showed a decrease in feto-placental ratio as compared to the control group. The ratio is more decreased in severe hypertensive group (5.28) as compared to control group (5.9), whereas normal fetoplacental ratio varies from 6.35 to 7.9 (Table 1).

One case $(4.34 \%)$ showed Gr. I change before 34 weeks and one case (4.34\%) showed after 34 weeks. All 21 cases showing Grade 'III' changes before 34 weeks had infarction, calcification, increased syncytial knots, fibrinoid necrosis from 95.23 to $100 \%$ of these cases showed all these changes (Figure 1 to 4). Only 2 cases $(9.52 \%)$ showed perivascular hemorrhage having Grade III before 34 weeks. After 34 weeks, 13 cases $(68.42 \%)$ showed grade III change had infarction, 8 cases $(42.10 \%)$ had calcification, 10 cases $(52.63 \%)$ had increased 
syncytial knots and 17 cases $(89.47 \%)$ had fibrinoid necrosis (Table 2).

One case had hemorrhage in Wharton's jelly. Two cases $(4.76 \%)$ had to be terminated having grade I changes, due to high BP, histopathologically had infarction and fibrinoid necrosis. Another 2 cases $(4.76 \%)$ developed eclampsia and one case $(2.38 \%)$ had essential hypertension.

Infarction was present in 2 cases $(6.8 \%)$ after 34 weeks which showed grade III changes. In 3 cases $(23.07 \%)$ showed grade II changes after 34 weeks, 14 cases (48.2\%) had calcification, these cases showed grade 'III' changes after 34 weeks (Table 3). None of the control group had perivascular hemorrhage or sub-chorionic haemorrhage.

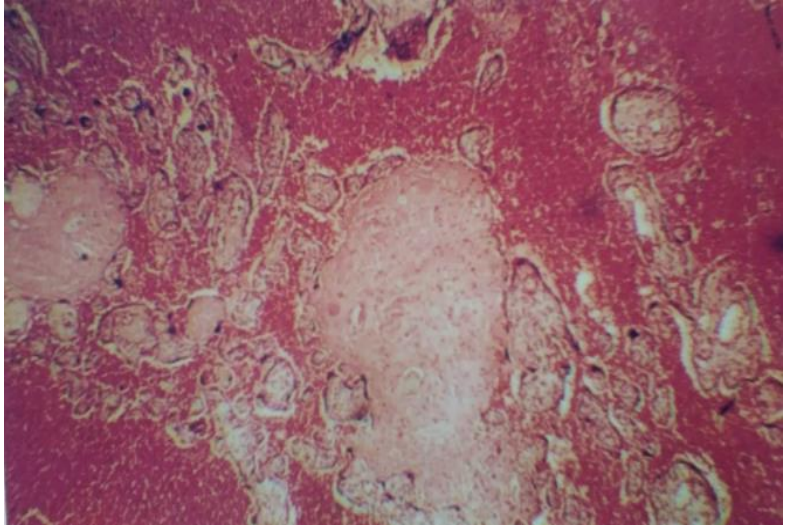

Figure 2: Placenta with extensive calcification in patient with pregnancy induced hypertension.

Table 3: Histopathological changes in placenta with ultrasound grading in control group.

\begin{tabular}{|llllll|}
\hline HIPR & Less than 34 weeks $(\mathbf{n = 4 2})$ & \multicolumn{2}{l|}{ More than 34 weeks } & & Total \\
\hline Infarction & Gr. II & Gr. III & Gr. II (n=13) & Gr. III (n=29) & \\
\hline Calcification & - & - & $3(23.07 \%)$ & $2(6.8 \%)$ & $5(11.90 \%)$ \\
\hline Increased syn. Knots & - & - & $7(53.84 \%)$ & $14(48.2 \%)$ & $21(50.00 \%)$ \\
\hline Fibrinoid necrosis & - & - & - & $4(13.7 \%)$ & $04(9.52 \%)$ \\
\hline Perivasc. Haemorrhage & - & - & $3(23.07 \%)$ & $9(31.03 \%)$ & $12(28.57 \%)$ \\
\hline Subchorionic haemorrhage & - & - & - & - & - \\
\hline
\end{tabular}

Table 4: Fetal outcome in study group.

\begin{tabular}{|c|c|c|c|c|c|c|c|}
\hline \multirow{2}{*}{ Fetal outcome } & \multicolumn{2}{|l|}{ Grade I } & \multicolumn{2}{|l|}{ Grade II } & \multicolumn{2}{|l|}{ Grade III } & \multirow{2}{*}{$\begin{array}{l}\text { Total } \\
\%\end{array}$} \\
\hline & $<34$ weeks & >34 weeks & $<34$ weeks & >34 weeks & $<34$ weeks & >34 weeks & \\
\hline Fetal Distress & - & - & - & - & $10(23.81 \%)$ & $4(9.52 \%)$ & $14(33.33)$ \\
\hline APGAR <7 & - & - & - & - & $18(42.8 \%)$ & $10(23.8 \%)$ & $28(66.67)$ \\
\hline FSB & $1(2.38 \%)$ & - & - & - & & - & $1(2.38)$ \\
\hline IUD & $2(4.76 \%)$ & - & - & - & & - & $2(4.76)$ \\
\hline $\begin{array}{l}\text { Neonatal } \\
\text { death }\end{array}$ & - & - & - & - & $3(7.14 \%)$ & - & $3(7.14)$ \\
\hline IUGR & - & - & - & - & $3(7.14 \%)$ & - & $3(7.14)$ \\
\hline
\end{tabular}

Table 5: Fetal outcome in control group.

\begin{tabular}{|c|c|c|c|c|c|c|c|}
\hline \multirow{2}{*}{ Fetal outcome } & \multicolumn{2}{|l|}{ Grade I } & \multicolumn{2}{|l|}{ Grade II } & \multicolumn{2}{|l|}{ Grade III } & \multirow{2}{*}{$\begin{array}{l}\text { Total } \\
\%\end{array}$} \\
\hline & < 34 weeks & >34 weeks & $<34$ weeks & $>34$ weeks & $<34$ weeks & $>34$ weeks & \\
\hline Fetal distress & - & - & - & $1(2.38 \%)$ & - & $3(7.14 \%)$ & 4 \\
\hline APGAR <7 & - & - & - & $3(7.14 \%)$ & - & $1(2.38 \%)$ & 4 \\
\hline FSB & - & - & - & - & - & - & - \\
\hline IUD & - & - & - & - & - & - & - \\
\hline IUGR & - & - & - & - & - & $1(2.38 \%)$ & 1 \\
\hline Neonatal death & - & - & - & - & - & - & - \\
\hline
\end{tabular}

Fourteen cases $(33.33 \%)$ in the study group, out of which $10(23.81 \%)$ were showing Grade III changes before 34 weeks. Whereas foetal distress was seen in 3 cases (7.14\%) in the control group all of them had Grade 'III' changes after 34 weeks, as shown in Table 4. APGAR score less than 7 was seen in 28 cases $(66.67 \%)$ in the study group, as depicted in Table 4 . Of that, 18 cases $(42.85 \%)$ showing Grade III changes before 34 weeks and 10 cases $(23.80 \%)$ showed Grade III changes after 34 weeks. In the study group we had $1(2.38 \%)$ FSB and 2 $(4.76 \%)$ intrauterine death. All these cases were induced 
at 30 weeks due to uncontrolled blood pressure. In the control group, 4 had $(9.52 \%)$ foetal distress out of which $1(2.38 \%)$ had Grade II changes in placenta after 34 weeks, $3(7.14 \%)$ had Grade III changes in placenta only after 34 weeks. Four cases $(9.52 \%)$ in the control group had APGAR score less than 7 (Table 5). There were 3 $(7.14 \%)$ neonatal death in the study group which showed Grade III changes before 34 weeks. Similarly, 3 cases (7.14\%) had IUGR in the study group which had placental Grade III changes as compared to the control group where we had 1 (2.38\%) IUGR (Table 5). Thus, fetal mortality and morbidity was high in the study group as compared to the control group (Table 4 and 5).

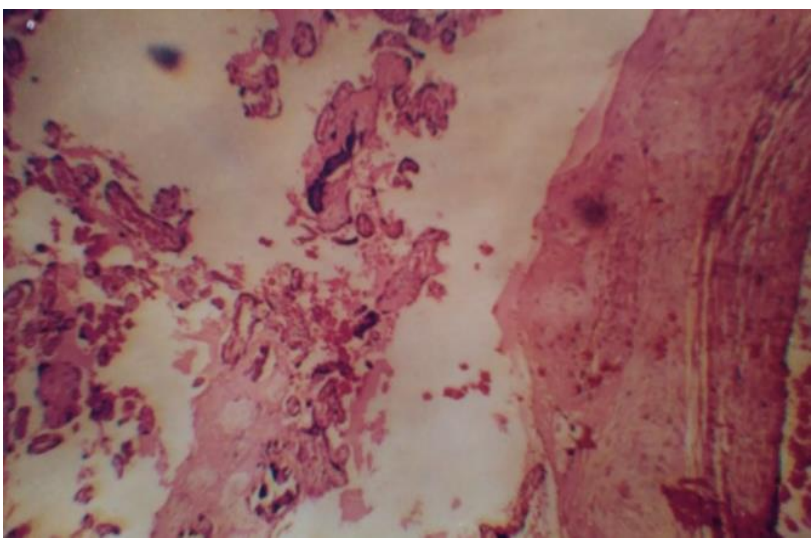

Figure 3: Placenta with syncytial and cytotrophoblastic proliferation in patient with pregnancy induced hypertension.

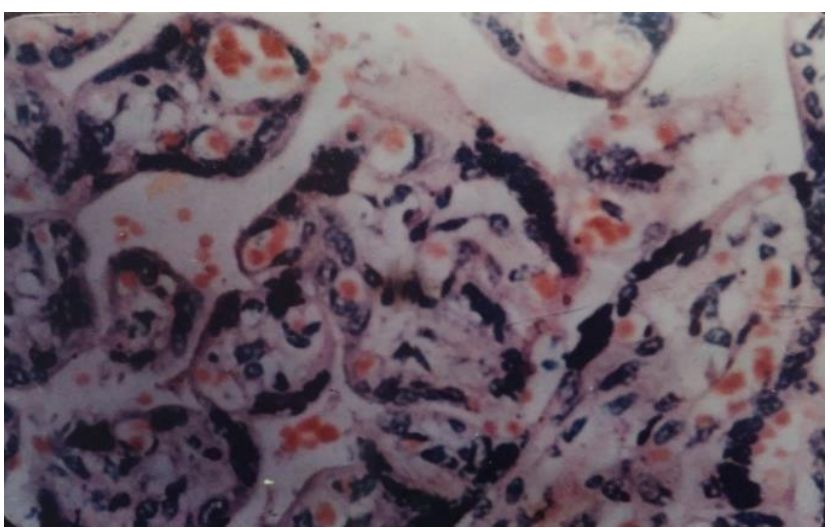

Figure 4: Placenta with increased formation of syncytial knots and cytotrophoblastic proliferation in patient with pregnancy induced hypertension.

\section{DISCUSSION}

The placenta starts organogenesis in the very early stage of embryogenesis, governs fetal growth, and terminates its own fate immediately after delivery. Placental perfusion is maintained by two distinct cardiovascular systems, ie, maternal blood fl ow and fetal circulation. Therefore, pathophysiology of the placenta is closely associated with both maternal status and fetal development. Among pregnancy-associated complications, eclampsia is an emergency condition for both mother and fetus. ${ }^{18} \mathrm{PIH}$ is characterized by blood pressure elevation after 20 weeks of gestation that is often accompanied by proteinuria (NHBPEP 2000). Genetic, immunologic, metabolic susceptibilities and other backgrounds have been investigated to understand the pathogenesis of this disease (Hiby et al, van Dijk et al, Hu et al, Johnson et al). ${ }^{19-22}$

Combined ultrasonic and histopathologic study have shown that the strong echoes detected ultrasonically during antenatal scanning of the placental correspond to deposits of fibrin and calcium. Caroll et al found $22.7 \%$ incidence of accelerated placental maturation out of 56 cases studied; in the present study, incidence of accelerated placental maturation was seen in $38.09 \%$ of cases before 34 weeks. $^{23}$

Fox is of the opinion that in uncomplicated pregnancy placental infarction play little role in perinatal mortality and morbidity. ${ }^{24,25}$ But extensive infarction as found in hypertensive in hypertensive complication of pregnancy is associated with high incidence of fetal hypoxia. This correlated with the present study where there was 18 out of 28 cases $(64.28 \%)$ showed APGAR Score $<7$ in the study group, where Grade-III changes are seen before 34 weeks, also showed histopathologic degenerative changes.

A significant increase in syncytial knot formation (Figure 3 ,4) in placental villi indicates the disturbance in the hormonal factors, which may probably lead to altered blood flow. According to Robertson, the cause of reduction in blood flow is due to vasculopathies of spiral arteries, which in turn causes reduction in the weight of placenta. It has been recorded that maternal uteroplacental blood flow is decreased in preeclampsia because of maternal vasospasm. Reduced maternal uteroplacental blood flow indirectly leads to constriction of fetal stem arteries. ${ }^{26}$

Pathological examination of human PIH placenta reveals diffuse fibrin deposition and acute atherosis in uteroplacental sites, i.e., mural fibrinoid necrosis of spiral arteries. With regard to fetoplacental circulatory unit, terminal villi are poorly differentiated, so called distal villous hypoplasia. Syncytial knots, i.e. aggregation of syncytiotrophoblastic nuclei, are also noted (Figure 3, 4). It is generally thought that such changes in PIH reflect placental hypoxia due to shallow invasion of extravillous trophoblasts at initial stage. However, it has not been answered whether acute atherosis and impaired neovascularization also occur by other predisposing factors, e.g., accelerated AT1 signaling. ${ }^{18}$

The preeclamptic women will have a lower mean gestation, so the proportion of fetal capillaries will be lower. The capillaries become larger as the gestation proceeds. This relative increase in fetal capillary volume with decrease in proportion of connective tissue will lead 
to smaller parenchymal volume leading to decrease in placental weight. ${ }^{26}$ The preeclamptic women will have a lower mean gestation, so the proportion of fetal capillaries will be lower. The capillaries become larger as the gestation proceeds. This relative increase in fetal capillary volume with decrease in proportion of connective tissue will lead to smaller parenchymal volume leading to decrease in placental weight. ${ }^{26}$

The primary cause of PE is the widespread apoptosis of cytotrophoblast cells. The invasion of uterine spiral arterioles by trophoblasts is limited to the superficial portions of the decidua, and $30-50 \%$ of these arterioles in the placental bed escape trophoblast remodeling. The mean luminal diameter of uterine spiral arterioles in women with PE is less than one-third of the diameter of similar vessels from uncomplicated pregnancies. The uteroplacental perfusion is as such reduced, and the placenta becomes ischemic as gestation progresses. This causes fetal hypoxia as well as morphological and histological changes in the placenta, leading to PE or PEassociated IUGR, which contributes to premature delivery and fetal death. ${ }^{27}$

Diagnostic procedures during pregnancy complicated with pregnancy-induced hypertension/ preeclampsia include clinical examinations (periodical blood pressure measuring), ultrasound examinations, laboratory testing, fetal well-being assessments. Detailed ultrasound examination of the fetus at 18-20 weeks also includes placenta-related information beyond the fetal measurements and morphology: determination of placental length and thickness, number of cord vessels, cord insertion, and the assessment of placental texture. Uterine artery Doppler evaluation is performed by color and pulsed Doppler mapping. Mean pulsatility index (PI) values $>1.45$ or bilateral early diastolic notches are considered abnormal. ${ }^{28-30}$

Placental infarction of more than $5 \%$ surface area was considered pathological as it was significantly more frequent in cases of toxemia as stated by Mirchandani et al, in their study. ${ }^{31}$ They studied 100 patients and stated that extensive infarction was found in the hypertensive group, is associated with incidence of fetal hypoxia. This correlates with present study where it was seen that infarction, calcification, necrosis was seen to the extent of $95.5 \%$ in the study group where, there was Grade-III changes before 34 weeks.

Nahar L et al showed macroscopic study of the placenta revealed placental weight, surface area and number of cotyledons were less in study group. ${ }^{32}$ In $\mathrm{PIH}$ group syncytial knots (95\%), fibrinoid necrosis (80\%), VSM (vasculosyncytial membrane) formation, sclerosis, chorangiosis and calcification were more marked. Infarction was present in placenta of PIH 34 (85\%) and in control group $8(20 \%)$. There was a tendency of lowering the weight of neonate $2.47 \mathrm{~kg}$ in study group and $3.06 \mathrm{~kg}$ in control group $(\mathrm{p}<0.001)$, number of asphyxiated babies and perinatal morbidity and mortality (still birth was 7.5 and neonatal death was $15 \%$ ) were more marked in PIH group. In PIH group placental changes were related with fetal outcome. Common placental changes were significant in this study. ${ }^{32}$

In the present study it is seen feto-placental ratio in study group showed a decrease in feto-placental ratio as compared to the control group. The ratio is more decreased in severe hypertensive group (5.28) as compared to control group (5.9), whereas normal fetoplacental ratio varies from 6.35 to 7.9 . In the present study, the weights of the placenta in study groups were below $500 \mathrm{~g}$. The least weight recorded being $230 \mathrm{~g}$. The observations correlate well with the previous studies done by various workers. Bazaz et al reported five cases of toxemia with placental weight less than 300 g. ${ }^{33}$ Nobis and Das, in their study, observed that the placental weight in toxemic cases varies from 279 to 407 g. ${ }^{34}$ Bhatia et al, in their study, have shown reduced placental weight in severe toxemia, the lowest recorded was $280 \mathrm{~g} .{ }^{35}$ The change in placental weight observed in the present study between the control group and study groups were statistically significant.

Salmani D et al observed, the average feto-placental weight ratio in normal pregnancy was $5.72 \pm 0.93$, $6.35 \pm 2.05$ in preeclamptic cases, and $6.44 \pm 2.02$ in eclamptic cases. ${ }^{8}$ The values corelate with the earlier study by Majumdar et al. ${ }^{36}$ Salmani D et al observed that the weight of the placenta was less in preeclampsia and eclampsia when compared with normal placenta. ${ }^{8}$ The mean neonatal birth weight was more in normal pregnancy $(3.14 \mathrm{~kg})$. It was less in preeclamptic and eclamptic cases $(<2.5 \mathrm{~kg})$. The feto-placental weight ratio was significantly higher in the hypertensive group than in the control group. Histological study of placenta showed significant number of syncytial knots, fibrinoid necrosis, areas of calcification and hyalinisation and areas of medial coat proliferation of medium sized blood vessels in the hypertensive group, whereas the control group showed normal histological features. ${ }^{8}$

In the study group, the histology revealed various structural changes such as significant number of syncytial knots, areas of fibrinoid necrosis, areas of medial coat proliferation of medium sized blood vessels, areas of calcification, and areas of hyalinization (Figure 1). A significant increase in syncytial knot formation in placental villi indicates the disturbance in the hormonal factors, which may probably lead to altered morphometry of placenta resulting in PIH in the mother and to low birth weight babies. Microscopic findings of localized fibrinoid necrosis, medial coat proliferation of arteries, and hyalinization depict the mosaicism of placenta and probably the aftermath of hypertension. ${ }^{37}$ Again the mosaicism of the placenta probably leads to placental insufficiency and ultimately to fetal growth retardation, thus creating a vicious cycle. ${ }^{38}$ 
Grannum et al could demonstrate the changes by ultrasonography and graded placental changes according in Grade-0, Grade-I, Grade-II, and Grade-III. ${ }^{17} \mathrm{He}$ also states that there is accelerated grading of placenta in toxemia of pregnancy. But the exact percentage in their study is not mentioned.

Quinlan and Cruz et al started that out of 41 patients studied, $3(7 \%)$ had placental abruption. ${ }^{39,40}$ But in the present study there was no cases of abruption in the study group nor in the control group. On the contrary, there was 3 cases $(7.14 \%)$ had sub-chorionic haemorrhage on ultrasonography, and all of these neonates developed fetal distress.

Hill et al studied 128 high risk and 60 healthy gravidas between 28 weeks and term, comparing placental grade, risk factor and gestational age. ${ }^{41,42}$ They found a strong positive correlation among accelerated placental maturation with hypertension and intrauterine growth retardation. But exact percentage were not indicated in the study. In this present study, $45 \%$ of cases showed low APGAR score and these cases also showed Grade-III placental changes before 34 weeks.

Damania et al stated that pathological changes increased as the hypertension increased as the hypertension increases the fetoplacental ratio decreases with increased toxemia. ${ }^{43}$ In their study, they got value to the extent of 5.71 , in the severe hypertensive group as compared to mild to hypertensive group 5.97. In the present study, the fetoplacental ratio was 5.2 in the severe hypertensive group and 5.4 in mild hypertensive group.

Chin-chiu, Marshall D et al studied 157 patients of which 95 were pre-eclamptic. ${ }^{44}$ In their study, they had 6 neonatal deaths of which 4 were due to complications of prematurity. This results correlates with the present study, where there were 3 neonatal deaths and mainly due to complication of prematurity, there was no neonatal death in control group.

\section{CONCLUSION}

To summaries, the finding of Grade-III changes in placenta in pregnancies complicated with hypertension may be clinically useful in two ways:

Grade III changes in the complicated study group and the old concept of post maturity is really, certainly not post mature but accelerated maturation and degenerative changes of the placenta. The term placental Insufficiency should be very cautiously used for in most cases, its use reflects attention away from the true cases (i.e. hypertension) and treated promptly, which may cause failure of fetal growth and neonatal complications. The technique holds the definite promise since it is noninvasive, rapid, safe evaluation of fetal status in pregnancies complicate with hypertension. Further, studies will be required to evaluate the significance of these findings in the complicated pregnancy.

Sonographic images associated with placental lesions include cystic areas, heterogeneous appearance of the placental mass, and thick or thin placentas. Sonographic evidence of destructive placental lesions is defined as the evolution of irregular cystic spaces with echogenic borders - the echogenic cystic lesions. Histological examinations of placenta may confirm these antepartum observations.

In addition, unexpected Grade-III changes in pregnancies complicated with hypertension may predict the development of late pregnancy problems in that pregnancy, though present study did not face such problems (e.g. abruptio). Accelerated maturation of placenta in pregnancy complicated with hypertension are more common in the hypertensive group. Increased histopathological degenerative changes e.g. calcification, fibrinoid necrosis etc., are more marked even before 34 weeks of gestation in hypertensive group. PIH significantly affects the placenta by reducing its weight and dimensions. These changes may cause placental insufficiency as a result of compromised utero-placental blood flow. Therefore, has an adverse effect on the neonatal birth weight. PIH has definite influence on morphology, histology of placenta, and thus affects the growth of the fetus. Finding of accelerated grading in hypertensive group will alert the Obstetrician so far as neonatal outcome is concerned.

Funding: No funding sources

Conflict of interest: None declared

Ethical approval: The study was approved by the Institutional Ethics Committee

\section{REFERENCES}

1. Palacios C, Pena-Rosas JP. Calcium supplementation during pregnancy for preventing hypertensive disorders and related problems. WHO RHL Commentary. Available from: http://apps.who.int/rhl/pregnancy_childbirth/ antenatal_care/nutrition/cd001059_penasrosasjp_co m/en/. [Accessed 19/01/2017].

2. Arshad A, Pasha W, Khattak TA, Kiyani RB. Impact of pregnancy induced hypertension on birth weight of newborn at term. JRMC. 2011;15(2):113-5.

3. Sibai BM. Diagnosis and management of gestational hypertension and preeclampsia. Obstet Gynecol. 2003;102(1):181-92.

4. Report of the National High Blood Pressure Education Program Working Group on High Blood Pressure in Pregnancy. Am J Obstet Gynecol. 2000;183(1):S1-S22.

5. Bewly S, Cooper D, Campbell S. Doppler investigation of utero-placental blood flow resistance in the second trimester. A screening study for pre- 
eclampsia and intra-uterine growth retardation. $\mathrm{Br} \mathrm{J}$ Obst Gynaecol. 1991;98:871-9.

6. Stock MK, Anderson DF, Phernetton TM, McLaughlin MK, Rankin JH. Vascular response of the maternal placental vasculature. J Dev Physiol. 1980;2:239-46.

7. Thomson AM, Billewickz, Hytten FE. Placenta in relation to birth weight. J Obstet Gynecol $\mathrm{Br} \mathrm{CW}$. 1969;76:865-72.

8. Salmani D, Purushothaman S, Somashekara SC, Gnanagurudasan E, Sumangaladevi K, Harikishan Ret al. Study of structural changes in placenta in pregnancy-induced hypertension. J Nat Sci Biol Med. 2014;5(2):352-55.

9. Brosens JJ, Pijnenborg R, Brosens IA. The myometrial junctional zone spiral arteries in normal and abnormal pregnancies: a review of the literature. Am J Obstet Gynecol. 2002;187(5):1416-23.

10. Gaccioli F, Lager S, Sovio U, Charnock-Jones DS, Gordon CS, Smith GCS. The pregnancy outcome prediction (POP) study: Investigating the relationship between serial prenatal ultrasonography, biomarkers, placental phenotype and adverse pregnancy outcomes. Placenta. 2016

11. Giordano R, Cacciatore A, Romano M, Rosa BL, Fonti I, Vigna R. Uterine artery Doppler flow studies in obstetric practice. J Prenat Med. 2010;4(4):59-62.

12. Salavati N, Sovio U, Mayo RP, Charnock-Jones DS, Smith GC. The relationship between human placental morphometry and ultrasonic measurements of utero-placental blood flow and fetal growth. Placenta. 2016;38:41-8.

13. Smith GC, Yu CK, Papageorghiou AT, Cacho AM, Nicolaides KH. Fetal medicine foundation second trimester screening, maternal uterine artery Doppler flow velocimetry and the risk of stillbirth. Obstet Gynecol. 2007;109(1):144-51.

14. Yu CK, Smith GC, Papageorghiou AT, Cacho AM, Nicolaides KH. Fetal medicine foundation second trimester screening, an integrated model for the prediction of preeclampsia using maternal factors and uterine artery Doppler velocimetry in unselected low-risk women. Am J Obstet Gynecol. 2005;193(2):429-36.

15. Chauhan SP, Rouse DJ, Ananth CV, Magann EF, Chang E, Dahlke JD, et al. Screening for intrauterine growth restriction in uncomplicated pregnancies: time for action. Am J Perinatol. 2013;30(1):33-9.

16. Sovio U, White IR, Dacey A, Pasupathy D, Smith GC. Screening for fetal growth restriction with universal third trimester ultrasonography in nulliparous women in the Pregnancy Outcome Prediction (POP) study: a prospective cohort study. Lancet. 2015;386(10008):2089-97.

17. Grannum PA, Berkowitz RL, Hobbins JC. The ultrasonic changes in the maturing placenta and their relation to fetal pulmonic maturity. Am J Obstet Gynecol. 1979;133(8):915-22.

18. Furuya M, Ishida J, Aoki I, Fukamizu A. Pathophysiology of placentation abnormalities in pregnancy-induced hypertension. Vasc Health Risk Managem. 2008;4(6):1301-13.

19. Hiby SE, Walker JJ, O'shaughnessy KM, Redman CWG, Carrington M, Trowsdale $\mathrm{J}$ et al. Combinations of maternal KIR and fetal HLA-C genes influence the risk of preeclampsia and reproductive success. J Exp Med. 2004;200:957-65.

20. van Dijk M, Mulders J, Poutsma A, Könst AAM, Lachmeijer AMA, Dekker GA et al. Maternal segregation of the Dutch preeclampsia locus at 10 q22 with a new member of the winged helix gene family. Nat Genet. 2005;37:514-9.

21. Hu Y, Dutz JP, MacCalman CD, Yong P, Tan R, von Dadelszen P. Decidual NK cells alter in vitro first trimester extravillous cytotrophoblast migration: a role for IFN-gamma. J Immunol. 2006;177:8522-30.

22. Johnson MP, Fitzpatrick E, Dyer TD, Jowett JB, Brennecke SP, Blangero J et al. Identification of two novel quantitative trait loci for pre-eclampsia susceptibility on chromosomes $5 \mathrm{q}$ and $13 \mathrm{q}$ using a variance components-based linkage approach. Mol Hum Reprod. 2007;13:61-7.

23. Carroll B. Ultrasonic features of preeclampsia. J Clin Ultrasound. 1980;8(6):483-8.

24. Fox H. The significance of placental infarction in perinatal morbidity and mortality. Biol Neonat. 1967;11(1):87-105.

25. Fox H. The morphological basis of placental insufficiency. J Obstet Gynaecol India. 1975;25:44150.

26. Boyd PA, Scott A. Quantitative structural studies on human placenta associated with preeclampsia essential hypertension and intrauterine growth retardation. Br J Obstet Gynaecol. 1985;92:714-21.

27. Predoi C, Grigoriu C, Vladescu R, Mihart A. Placental damages in preeclampsia-from ultrasound images to histopathological findings. J Med Life. 2015;8:62-5.

28. Kleinrouweler CE, Bossuyt PM, Thilaganathan B, Vollebregt KC, Ramírez JA, Ohkuchi A, et al. The added value of second trimester uterine artery Doppler in the identification of nulliparous women at increased risk for pre-eclampsia. Am J Obstet Gynecol. 2012;20:182-3.

29. Reis NS, Brizot ML, Schultz R, Nomura RM, Zugaib M. Placental lakes on sonographic examination: Correlation with obstetric outcome and pathologic findings. J Clin Ultrasound. 2005;33:67-71.

30. Scission A, Hayes E. Uterine artery Doppler Flow studies in obstetric practice. Am J Obstet Gynecol. 2009;201:121-6.

31. Mirchandani JJ, Mallik GB, Chitra S. Correlation of foetal outcome with some pathological changes of placenta. J Obstet Gynaecol India. 1979;29:1131-9.

32. Nahar L, Nahar K, Hossain MI, Yasmin H, Annur BM. Placental changes in pregnancy induced hypertension and its impacts on fetal outcome. Mymensingh Med J. 2015;24(1):9-17. 
33. Bazaz G, Mirchandani JJ, Chitra S. Placenta in intrauterine growth retardation. J Obstet Gynecol India. 1979;29:805-10.

34. Nobis P, Das U. Placental morphology in hypertensive pregnancy. J Obstet Gynecol. 1991;41:166-9.

35. Bhatia A, Sharma SD, Jalnawalla SF, Sagreiya K. A comparative study of placental and foetal outcome. Indian J Pathol Microbiol. 1981;24:277-83.

36. Majumdar S, Dasguptha $\mathrm{H}$, Bhattacharya $\mathrm{K}$, Bhattacharya A. A study of placenta in normal and hypertensive pregnancies. J Anat Soc India. 2005;54:34-8.

37. Teasdale F. Gestational changes in functional structure of the human placenta in relation to foetal growth. Am J Obstet. 1980;137:560-2.

38. Zacutti A, Borruto F, Bottacci G, Giannoni ML, Manzin A, Pallini M et al. Umbilical blood flow and placental pathology. Clin Exp Obstet Gynaecol. 1992;19:63-9.

39. Quinlan RW, Cruz AL, Buhi WC, Martin M. Changes in placental ultrasonic appearance. II. Pathologic significance of grade III placental changes. Am J Obstet Gynecol. 1982;144:471-3.
40. Quinlan RW, Cruz AL, Buhi WC, Martin M. Changes in placental ultrasonic appearance. I. Incidence of grade III changes in the placenta in correlation to fetal pulmonary maturity. Am J Obstet Gynecol. 1982;144:468-70.

41. Hill LM, Breckle R, Ragozzino MW, Wolfgram KR, O'Brien PC. Grade 3 placentation: incidence and neonatal outcome. Obstet Gynecol. 1983;61:728-32.

42. Hills D, Irwin GA, Tuck S, Baim R. Distribution of placental grade in high-risk gravidas. American Journal of Roentgenology. 1984;143:1011-3.

43. Damania KR, Salvi VS, Ratnaparki SK, Daftari SN. The placenta in hypertensive disorder in pregnancy. $\mathbf{J}$ Obst and Gynaecol Ind. 1989;39:28-31.

44. Lin CC, Lindheimer MD, River P, Moawad AH. Fetal outcome in hypertensive disorders of pregnancy. Am J Obstet Gynecol. 1982;142(3):25560 .

Cite this article as: Dutta A, Sahu RK, Chatterjee K, Kothari S, Rahaman SKR, Sen S. Placental damages from ultrasonic changes to histopathological findings in maturing placenta in pregnancy complicated with hypertension: an observational clinical study. Int J Reprod Contracept Obstet Gynecol 2017;6:1834-42. 